Study Report 2001-02

\title{
Issues of Adaptive Automated Surveys in a Computer Network Environment
}

\author{
Elliot E. Entin, Caroline Kerrigan, \\ Michael Berbaum, Patrice Lancey, and \\ Debra McCallum \\ ALPHATECH, Inc.
}

\section{Army Personnel Survey Office \\ Morris P. Peterson, Chief}

\section{U.S. Army Research Institute for the Behavioral and Social Sclences 5001 Elsenhower Avenue, Alexandria, Virginia 22333-5600}

February 2001

Approved for public release; distribution is unlimited. 